\title{
Study on Parameter Optimization of Concave Disc Copying Icebreaking Snow Sweeper
}

\author{
Li Yaqin ${ }^{1,2}$, WuWenfu ${ }^{1}$, Wang Junfa ${ }^{2 *}$, Li Xiaoxia $^{2}$ and Wang Rui ${ }^{2}$ \\ ${ }^{1}$ Biological and Agricultural Engineering college, Jilin University, Changchun \\ 130022, China; \\ ${ }^{2}$ College of Mechanical Engineering, Jiamusi University, Jiamusi 154007, China \\ Author: liyaqin20020702@163.com \\ *Corresponding Author: wangjunf2934@sina.com
}

\begin{abstract}
A concave disc copying icebreaking snow sweeper has been developed for improving the work efficiency and clearing free rate of solid ice and snow, and meeting the rapidity and efficiency of solid snow removal. The machine can simultaneously complete five functions of crush, chop, lifting, scraping and pushing, which also can realize independent servo-copying and self-excited vibrations reduction drag avoidance functions. The structure and working principle of the concave disc copying icebreaking snow sweeper have been introduced. The optimal combination of operating parameters impact on the clearing free rate and efficiency has been determined. The combinatorial optimization test methods of quadratic regression orthogonal rotation center was adopted, the traveling speed, digging depth of the snow, the blade angle of concave, the travel angle of concave blade are made as mpacting factors, snow resistance, the clearing free rate, the maximum volume of removing snow pack as the objective function, optimizing experimental studied on the impact of performance of the snow machine operating parameters. The results showed that: the effect of copying and crossing obstacle in machine is good, effectively solve the problem of low clearing free rate of solid ice, while the efficiency of snow removal has been improved. According to the principle of objective function: the smaller snow resistance, the higher clearing free rate, the maximum volume of snow pack, making each factor level interval as constraint optimization, when the snow resistance is smaller than $820 \mathrm{~N}$, the clearing free rate is greater than 96\%, the moximum volume of snow pack is smaller than 612mm3, the traveling speed ranges from $6 \mathrm{~km} / \mathrm{h}$ to $9.7 \mathrm{~km} / \mathrm{h}$, the blade angle of concave blade is 19 $21^{\circ}$, the travel angle of concave blade is $12^{\circ} \sim 14^{\circ}$. The above operating parameters are the optimal combination of snow machines.
\end{abstract}

Keywords:solid ice and snow; icebreaking snow sweeper; design expert; test analysis; parameler optimization

\section{Introduction}

The snowfall is not cleared timely on road surface in winter , which makes the road form a hard, complex components of a mixture of snow and ice repeatedly rolled by vehicles and pedestrians, coupled with repeated thawing and automobile exhaust intervention, this kind of snow collectively is called solid ice and snow. All along, The problem that how to efficiently clear solid ice and snow, which always plagues the staff [1-3].According to the survey[4],the accidents caused by the road snow compacted freezing about $35 \%$ of the total accidents in winter, causing huge losses to the national economy. Through the existing research [8-10] of snow clearing machines find that the existing solid snow clearing machine prevalent not quickly cleared, complex structure, 
copying function is poor, severe damage to the road surface, without obstacle avoidance function, damage to the roads and snow clearing tools, low clearing free rate and other issues restricting the promotion of snow clearing machine. In this paper, the clearance test of solid ice and snow is performed by using the self-developed concave disc copying icebreaking snow sweeper, exploring the optimal combination of the machine structure and working parameters, providing a theoretical basis for the product design type of solid ice and snow clearing machine.

\section{Concave Disc Copying Icebreaking Snow Sweeper}

According to the serious shortcomings [11-13] that low snow clearing efficiency, low clearing free rate and damage to the road surface exist in the current solid ice and snow clearing machine, the disc harrow is transformed and innovatively designed the concave disc copying icebreaking snow sweeper based on its application in agriculture cultivator. The snow clearing machine working width $2000 \mathrm{~mm}$, working efficiency $5000 \mathrm{~m} 2 / \mathrm{h}$, is mainly composed of power machinery, frame, concave disc copying snow institutions and obstacle avoidance scraping snow agencies, can be completed the five fun tions for road surface of solid ice and snow once time. The structure and composition are shown in Figure 1.

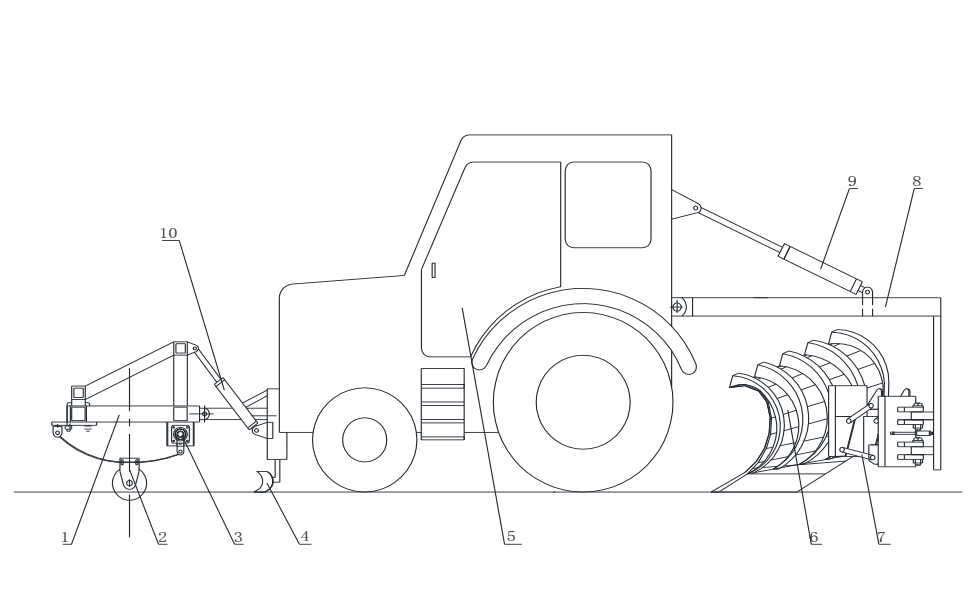

1. First Frame 2. Concave Snow Sweeper 3. Eccentric Vibratory Mechanism 4.Small Shovels 5.Power Machinery 6. Shovel of Scraping Snow 7. The Obstacles-Avoiding Mechanism of Scraping Snow Shovel 8.Second Frame 9.First Hydraulic Cylinder 10.Second Hydraulic Cylinder
0.S

Figure 1. Schematic diagram of Concave Disc Copying Icebreaking Snow Sweeper

The key components of snow clearing machine, concave disc copying snow clearing copying mechanism, is monomer copying, hanged in the front of power machinery, and mainly composed of concave disc, eccentric agencies. Concave disc is connected with the rack and eccentric vibration mechanism by the both ends of leaf springs. The eccentric mechanism can achieve chop-shovel style clearing snow in working, while taking advantage of the friction between ice and snow and the side thrust of concave disc applied by snow achieve the five functions that crushing, cutting, lifting, scraping and pushing to snow. A pair of small shovel is fitted on the front wheel of power machinery, pushing the cleared snow to the lateral of the wheel, in case of the cleared snow rolled again. The three-point suspension in the rear of power machinery with obstacle avoidance scraping snow mechanism consists of frame, scraping snow shovel and obstacle avoidance agencies. In the course of work, the snow scraping shovel can be adjusted the angle of the side push by two hydraulic cylinders, pushes the snow that have been cleared by concave disc copying snow clearing machine and pushed lateral by the front side shovel to the sides of the road, achieve the overall snow removal operations. 


\section{Equipment and Method}

\subsection{Test Equipment and Instruments}

Tianjin Deere 804 wheeled tractor, tension sensor, tape, steel ruler, hardness tester, thermometer, hygrometer, tachometer, stopwatch etc.

The road that 50 meters long, 6 meters wide in front of the Jiamusi University 118 experimental teaching building was selected as testing site, the snowfall on the road since the winter was formed the snow and ice that hard surface, solid inside by the compaction of pedestrians and vehicles, compliance with the test requirements of concave disc copying icebreaking snow sweeper clearing snow. Set three workplaces $(10 \mathrm{~m}$ each $)$ and two buffers $(5 \mathrm{~m}$ each) in testing, the test conditions of that day were shown in Table 1 .

Table 1. Test Conditions

\begin{tabular}{cccc}
\hline $\begin{array}{c}\text { temperatur } \\
\mathrm{e}\left({ }^{\circ} \mathrm{C}\right)\end{array}$ & $\begin{array}{c}\text { humidit } \\
\mathrm{y}(\%)\end{array}$ & $\begin{array}{c}\text { The average solid degrees of } \\
\text { snow and ice }(\mathrm{KPa})\end{array}$ & $\begin{array}{c}\text { The average density of snow and } \\
\text { ice }\left(\mathrm{kg} / \mathrm{m}^{2}\right)\end{array}$ \\
\hline-25 & 45 & 2582 & 743.6 \\
\hline
\end{tabular}

The optimization method of four factors and five levels two times regression orthogonal rotation center group was adopted in the test. A total or 36 sets of test[14] was implemented by using marching speed(x1), the snow depth(x2), concave disc blade angle(x3), the angle between concave disc and marching direction( $\mathrm{x} 4)$ as the affect factors, and snow clearing resistance $(y 1)$, clearing free rate $(y 2)$, the maximum volume of snow pack clearing (y3) as the objectie function, Date processing and analysis by using software Design-Expert 6.0.10[15], the each factor level determined according to the preliminary test and the operating practices of solid snow clearing, the test factors level code table shown in Table 2

\section{Table 2. Test Factors Level Code Table}

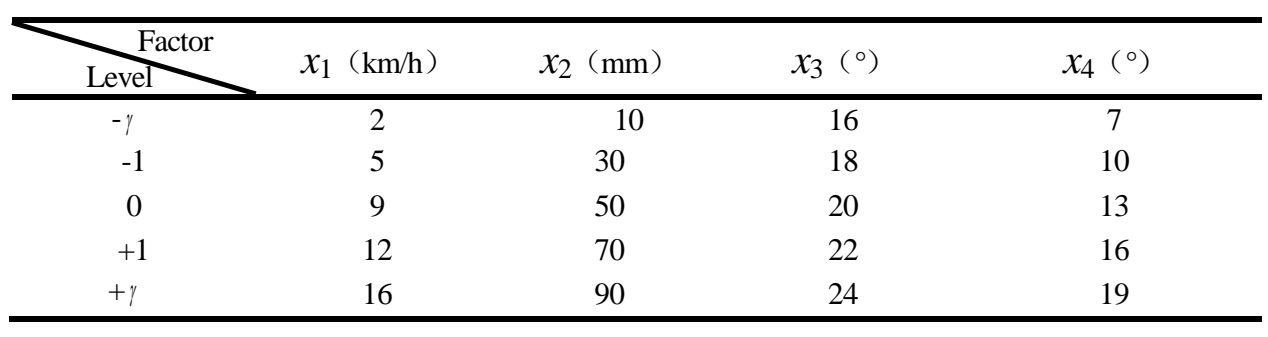

\section{The Trust Results and Analysis}

\subsection{The Trust Results}

The snow clearing test of concave disc copying icebreaking snow sweeper was concucted according to the pre-established test program, the test program and results shown in Table 3. 
Table 3. Experimental Scheme and Results

\begin{tabular}{|c|c|c|c|c|c|c|c|}
\hline \multirow{2}{*}{ Test No. } & \multirow{2}{*}{$x_{1}(\mathrm{~km} / \mathrm{h})$} & \multirow{2}{*}{$x_{2}(\mathrm{~mm})$} & \multirow{2}{*}{$x_{3}\left({ }^{\circ}\right)$} & \multirow{2}{*}{$x_{4}\left({ }^{\circ}\right)$} & \multicolumn{3}{|c|}{ Index } \\
\hline & & & & & $y_{1}(\mathrm{~N})$ & $y_{2}(\%)$ & $y_{3}\left(10^{-9} \mathrm{~m}^{3}\right)$ \\
\hline 1 & 5 & 30 & 18 & 10 & 915 & 95.5 & 630 \\
\hline 2 & 12 & 30 & 18 & 10 & 625 & 98.0 & 560 \\
\hline 3 & 5 & 70 & 18 & 10 & 945 & 93.3 & 654 \\
\hline 4 & 12 & 70 & 18 & 10 & 602 & 97.2 & 503 \\
\hline 5 & 5 & 30 & 22 & 10 & 872 & 93.3 & 563 \\
\hline 6 & 12 & 30 & 22 & 10 & 598 & 99.0 & 568 \\
\hline 7 & 5 & 70 & 22 & 10 & 903 & 93.4 & 735 \\
\hline 8 & 12 & 70 & 22 & 10 & 619 & 98.0 & 501 \\
\hline 9 & 5 & 30 & 18 & 16 & 590 & 92.5 & 622 \\
\hline 10 & 12 & 30 & 18 & 16 & 686 & 95.7 & 564 \\
\hline 11 & 5 & 70 & 18 & 16 & 1280 & 98.3 & 581 \\
\hline 12 & 12 & 70 & 18 & 16 & 744 & 98.2 & 618 \\
\hline 13 & 5 & 30 & 22 & 16 & 918 & 92.1 & \\
\hline 14 & 12 & 30 & 22 & 16 & 728 & 91.3 & 752 \\
\hline 15 & 5 & 70 & 22 & 16 & 1103 & 92.5 & 779 \\
\hline 16 & 12 & 70 & 22 & 16 & 1229 & 91.8 & 672 \\
\hline 17 & 2 & 50 & 20 & 13 & 805 & 97.0 & 653 \\
\hline 18 & 16 & 50 & 20 & 13 & 602 & 99.0 & 640 \\
\hline 19 & 9 & 10 & 20 & 13 & 745 & 91.0 & 595 \\
\hline 20 & 9 & 90 & 20 & 13 & 1113 & 94.0 & 785 \\
\hline 21 & 9 & 50 & 16 & 13 & 760 & 93.8 & 531 \\
\hline 22 & 9 & 50 & 24 & 13 & 8310 & 92.0 & 579 \\
\hline 23 & 9 & 50 & 20 & 7 & 703 & 93.0 & 432 \\
\hline 24 & 9 & 50 & 20 & 19 & 1152 & 93.0 & 625 \\
\hline 25 & 9 & 50 & & 13 & 805 & 95.0 & 658 \\
\hline 26 & 9 & 50 & & 13 & 795 & 96.0 & 659 \\
\hline 27 & 9 & 50 & 20 & 13 & 762 & 95.0 & 656 \\
\hline 28 & 9 & 50 & 20 & 13 & 780 & 96.0 & 603 \\
\hline 29 & 9 & & 20 & 13 & 796 & 95.0 & 624 \\
\hline 30 & 9 & 50 & 20 & 13 & 815 & 96.0 & 615 \\
\hline 31 & 9 & 50 & 20 & 13 & 784 & 94.0 & 582 \\
\hline 32 & & 50 & 20 & 13 & 791 & 98.0 & 624 \\
\hline 33 & & 50 & 20 & 13 & 783 & 96.0 & 601 \\
\hline 34 & & & 20 & 13 & 797 & 93.0 & 597 \\
\hline 35 & & 50 & 20 & 13 & 801 & 97.0 & 626 \\
\hline 36 & 9 & 250 & 20 & 13 & 798 & 95.0 & 585 \\
\hline
\end{tabular}

\subsection{Data Processing?}

4.2.1. Regression Equation and Significance Analysis: According to the analysis by using Design-Exper6.0.10, analysis of variance table objective function shown in Table 4.

Table 4. Analysis of Variance Table

\begin{tabular}{ccccccc}
\hline Source of variance & Sum of squared & Degree of free & Value of mean square & F value & Criticality \\
\hline Model & $8.521 \mathrm{E}+005$ & 9 & 94682.94 & 13.02 & $<0.0001$ \\
$x_{1}$ & $1.839 \mathrm{E}+005$ & 1 & $1.839 \mathrm{E}+005$ & 25.29 & $<0.0001$ \\
& $x_{2}$ & $2.070 \mathrm{E}+005$ & 1 & $2.070 \mathrm{E}+005$ & 28.47 & $<0.0001$ \\
& $x_{3}$ & 21901.04 & 1 & 21901.04 & 3.01 & 0.0945 \\
$y_{1}$ & $x_{4}$ & $1.832 \mathrm{E}+005$ & 1 & $1.832 \mathrm{E}+005$ & 25.20 & $<0.0001$ \\
& $x_{2}^{2}$ & 35934.34 & 1 & 35934.34 & 4.94 & 0.0351 \\
& $x_{4}^{2}$ & 35134.59 & 1 & 35134.59 & 4.83 & 0.0370 \\
& $x_{1} x_{4}$ & 29498.06 & 1 & 29498.06 & 4.06 & 0.0545 \\
& $x_{2} x_{4}$ & $1.182 \mathrm{E}+005$ & 1 & $1.182 \mathrm{E}+005$ & 16.25 & 0.0004 \\
& $x_{3} x_{4}$ & 37345.56 & 1 & 37345.56 & 5.14 & 0.0320 \\
\hline
\end{tabular}




\begin{tabular}{|c|c|c|c|c|c|c|}
\hline & $\begin{array}{c}\mathrm{e} \\
\text { Sum }\end{array}$ & $\begin{array}{l}1.891 \mathrm{E}+005 \\
1.041 \mathrm{E}+005 \\
\end{array}$ & $\begin{array}{l}26 \\
35 \\
\end{array}$ & 7271.87 & & \\
\hline \multirow{13}{*}{$y_{2}$} & Model & 146.35 & 11 & 13.30 & 8.16 & $<0.0001$ \\
\hline & $x_{1}$ & 16.34 & 1 & 16.34 & 10.02 & 0.0042 \\
\hline & $x_{2}$ & 15.32 & 1 & 15.32 & 10.75 & 0.0031 \\
\hline & $x_{3}$ & 12.62 & 1 & 12.62 & 7.73 & 0.0104 \\
\hline & $x_{4}$ & 5.80 & 1 & 5.80 & 3.56 & 0.0715 \\
\hline & $x_{1}^{2}$ & 17.50 & 1 & 17.50 & 10.73 & 0.0032 \\
\hline & $x_{2}^{2}$ & 12.92 & 1 & 12.92 & 7.92 & 0.0096 \\
\hline & $x_{3}^{2}$ & 9.17 & 1 & 9.17 & 5.62 & 0.0261 \\
\hline & $x_{4}^{2}$ & 8.34 & 1 & 8.34 & 5.11 & 0.0331 \\
\hline & $x_{1} x_{4}$ & 9.92 & 1 & 9.92 & 6.08 & 0.0212 \\
\hline & $x_{2} x_{3}$ & 11.90 & 1 & 11.90 & 7.30 & \\
\hline & $x_{3} x_{4}$ & 25.50 & 1 & 25.50 & 15.64 & \\
\hline & $\begin{array}{c}\mathrm{e} \\
\text { Sum }\end{array}$ & $\begin{array}{c}39.14 \\
185.49\end{array}$ & 24 & 1.63 & & \\
\hline \multirow{11}{*}{$y_{3}$} & Model & $1.347 \mathrm{E}+005$ & 9 & 962 & 7.25 & $<0.0001$ \\
\hline & $x_{1}$ & 11926.04 & 1 & 02 & & 0.0236 \\
\hline & $x_{2}$ & 9640.04 & 1 & & & 0.0401 \\
\hline & $x_{3}$ & 15862.04 & 1 & 62.04 & 69 & 0.0102 \\
\hline & $x_{4}$ & 37052.04 & 1 & 7052 & 17.95 & 0.0003 \\
\hline & $x_{2}^{2}$ & 13958.42 & & & 6.76 & 0.0151 \\
\hline & $x_{4}^{2}$ & 12155.00 & & & 5.89 & 0.0225 \\
\hline & $x_{1} x_{2}$ & 10050.06 & & & 4.87 & 0.0364 \\
\hline & $x_{1} x_{4}$ & 9555.06 & & & 4.63 & 0.0409 \\
\hline & $\begin{array}{c}x_{3} x_{4} \\
\mathrm{e}\end{array}$ & $\begin{array}{l}14460.06 \\
53662.86\end{array}$ & & $\begin{array}{c}14460.06 \\
2063.96\end{array}$ & 7.01 & 0.0136 \\
\hline & Sum & $1.883 \mathrm{E}+005$ & & & & \\
\hline
\end{tabular}

4.2.2. The Determination of Regression Equation: The $F$ test was adopted on the condition that the reliability of each regression coefficient was 0.05 lower in the regression equation of snow clearing resistance $\mathrm{y}_{1}$, the simplified regression equation was shown as formula (1) and was obtained by removing the non-significant items. Similarly, the simplified equation of clearing free date $y_{2}$ and the maximum volume of snow clearing pack $y_{3}$ can be obtained shown as formula (2),(3).

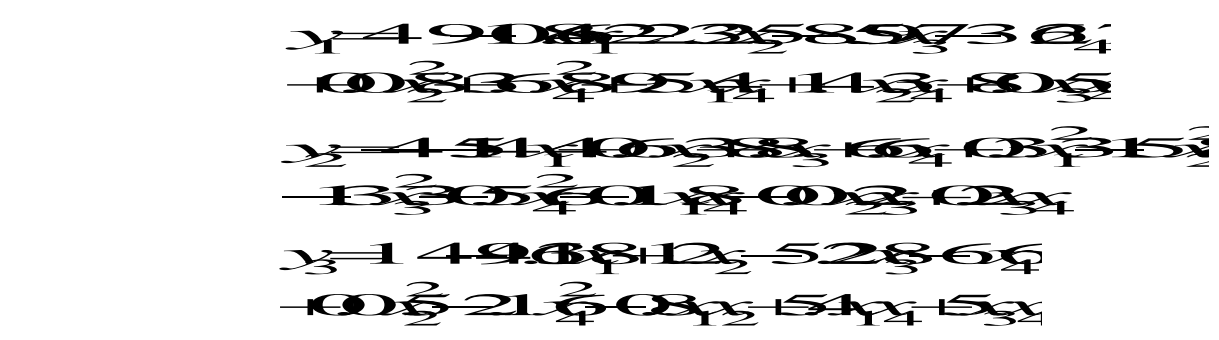

\subsection{The Analysis that each Factor Impact to Performance Indicators}

4.3.1. The Analysis of each Factors Impact to Snow Clearing Resistance: It can be seen that the objective function of snow clearing resistance y1 significantly affected by $\mathrm{x}_{1} \mathrm{x}_{4} 、 \mathrm{x}_{2} \mathrm{x}_{4} 、 \mathrm{x}_{3} \mathrm{x}_{4}$ according to the Analysis of variance table 4. The depth of snow and marching angle of concave disc, concave disc blade angle and marching angle of concave disc are interactions. 
Figure 2 (a) shows that with the decrease of marching angle of concave and the marching speed increases disc, which makes snow clearing resistance decreases and cutting blade ability to increase, The ice and snow is easily crushed and cut.

Figure 2 (b) shows that the snow clearing resistance is in the state that after the first increase reduce with the increase of marching angle of concave disc under the influence of the depth into the snow. The reason is that the adhesion between snow layer and road surface is large when the thickness of the snow layer smaller, and a flake bond can't been formed in the layers, the snow clearing resistance is larger at this time, the adhesion in snow layers increases with the increase of thickness of ice and snow, ice and snow easily forms a massive bond presented as large sheet fractures, chunks of ice and snow will fall and the snow clearing resistance is significantly reduced by the combined effect that applied by the share force and concave disc blade angle, in which the effect of "lift" plays a dominant role. But when the marching angle of concave disc reaches above $13^{\circ}$, the area that the concave disc acting on ice and snow is increased, and then the force increases so that the snow clearing resistance increases significantly.

It can be found in the Figure 2 (c) that snow clearing resistance increases rapidy with the increase of concave disc marching speed under the influence of the conoave disc blade angle, but the snow clearing resistance changes slowly, showing a slight decreasing trend with the increase of the blade angle.

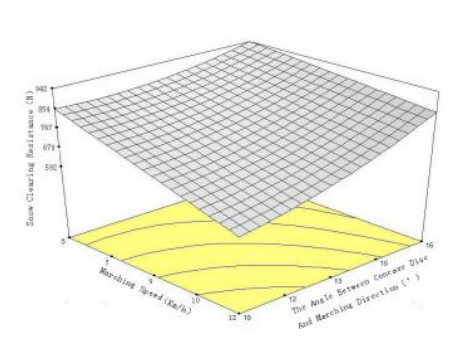

A. The Traveling Speed and the Blade Angle of Concave

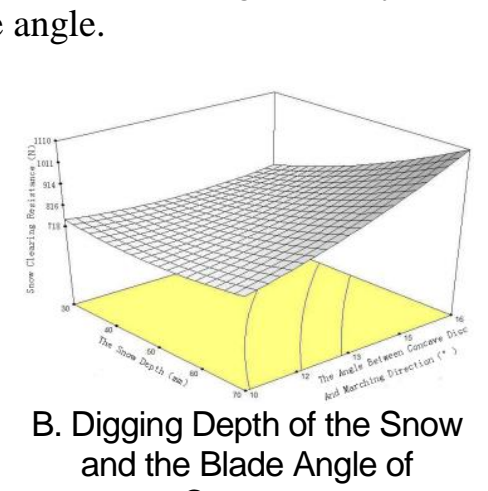

Xoncave

Figure 2. Response Surface of Effect on Response Functions of Snow Resistance

4.3.2 The Analysis of eachactors that Impact to the Clearing Free Rate: It can be seen that the objective function of the clearing free rate $\mathrm{y}_{2}$ significantly affected by $\mathrm{x}_{1} \mathrm{x}_{4}$ $\checkmark \mathrm{x}_{2} \mathrm{x}_{4} 、 \mathrm{x}_{3} \mathrm{x}_{4}$ according to the Analysis of variance Table 4. There are interactions between marching speed and marching angle of concave disc, depth into snow and concave disc blade angle, concave disc blade angle and marching angle of concave disc.

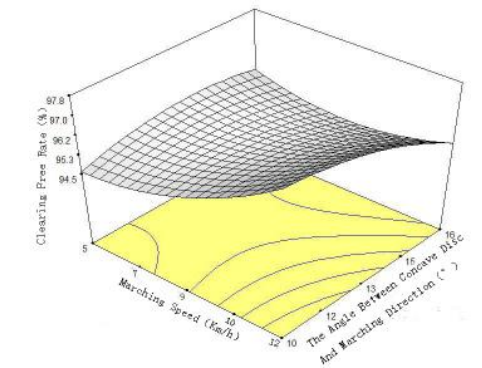

a. The Traveling Speed and the Blade Angle of Concave

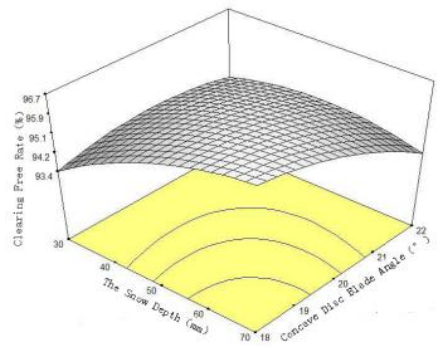

b. Digging Depth of the Snow and the Travel Angle of Concave Blade

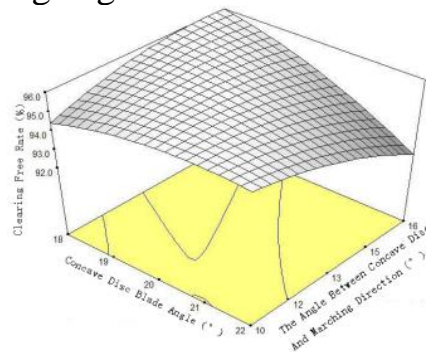

c. The Travel Angle of Concave Blade and the Blade Angle of Concave

Figure 3. Response Surface of Effect on Response Functions of the Clearing Free Rate 
It can be known in the Figure 3 (a) that the clearing free date firstly decreases and then increases with the increase of marching speed because of the influence of interaction between concave disc marching angle and marching speed. The reason is that the "press", "cut" function is significant, but the "lift" effect is not very good as the smaller marching angle of concave disc, especially the clearing free rate will be affected by the smaller omission appears at the junction of two concave disc, thus there is an optimum value in the concave disc marching angle so that the desired effect of snow clearing will be achieved.

It can be seen in the Figure 3 (b) that the clearing free rate firstly increases and then decreases with the increase of snow depth, the reason is that the thickness of snow layer has a certain influence on the adhesion properties of snow pack. The concave disc blade increases and the clearing free rate firstly increases and then decreases under the influence of depth into snow, because there is the concave disc blade angle playing a dominant role on the separation of the ice and snow on road surface, which has a greater influence on "cut", "lift", the concave disc blade angle is too smaller so that it will not act as a "lift" effect, while too large will impact on the "lift" effect, thereby affecting the clearng free rate.

According to the Figure 3 (c) finds that the clearing free rate shows a firstly increases and then decreases trend with the increase of concave disc blade angle and concave disc marching angle. The reason is that the snow clearing tool can't be achieved the $100 \%$ force on the area of ice and snow road surface on the conditions that the concave blade angle and the marching angle are smaller so that the clearing free rate is lower.

4.3.3. The Analysis of each Factors Impact to the Maximum Volume of Snow Pack Clearing: According to the Analysis of -variance table 4, It can be seen that the objective function of maximum volume of snow pack cleafing $y_{3}$ significantly affected by $x_{1} x_{4} 、 x_{1}$ $\mathrm{x}_{4} 、 \mathrm{x}_{3} \mathrm{x}_{4}$. There are interactions betyeen marching speed and depth into snow, marching speed and marching angle of concave dise, concave disc blade angle and marching angle of concave disc.

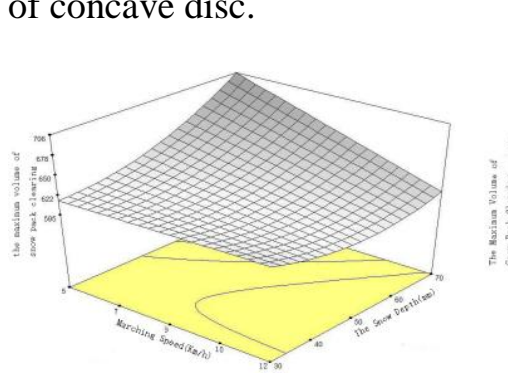

a. The Traveling Speed and Digging Depth of the Snow b. The Traveling Speed and the Blade Angle of Concave

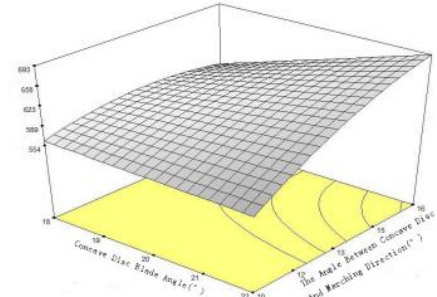

c. The Travel Angle of Concave Blade and the Blade Angle of Concave

\section{Figure 4. Response Surface of Effect on Response Functions of the Maximum Volume of Removing Snow Pack}

V can be known in the Figure 4 (a) that the maximum volume of snow pack clearing decreases slowly with the increase of marching speed, the reason is that increasing march speed makes the impact of ice and snow add, which generates the striking force. While the maximum volume of snow pack shows a firstly decreases and then increases trend with the increase of depth into the snow under the influence of marching speed.

It can be seen in the Figure 4 (b) that clearing the maximum volume of snow pack increases rapidly and leveling off finally with the increase of marching angle of concave disc. The reason is that the increase of the marching angle of concave disc makes the area of ice and snow increase, which the larger lump chip is generated, but when the marching 
angle of concave disc reaches $13^{\circ}$ above, clearing the maximum volume of snow pack almost reaches the maximum limit, the volume no longer increases.

It can be found in the Figure 4 (c) that the marching angle of concave disc is increased by the interaction between concave disc blade angle and concave disc marching angle, clearing the maximum volume of snow pack shows the tendency of increase rapidly. The reason is that the "press", "cut" effect can be completed by the concave disc blade angle, on the basis of the effect, the "lift" effect of concave disc marching angle can be achieved easily, thereby, the volume of snow pack shows the tendency of increase rapidly.

\subsection{The Analysis of Parameter Optimization}

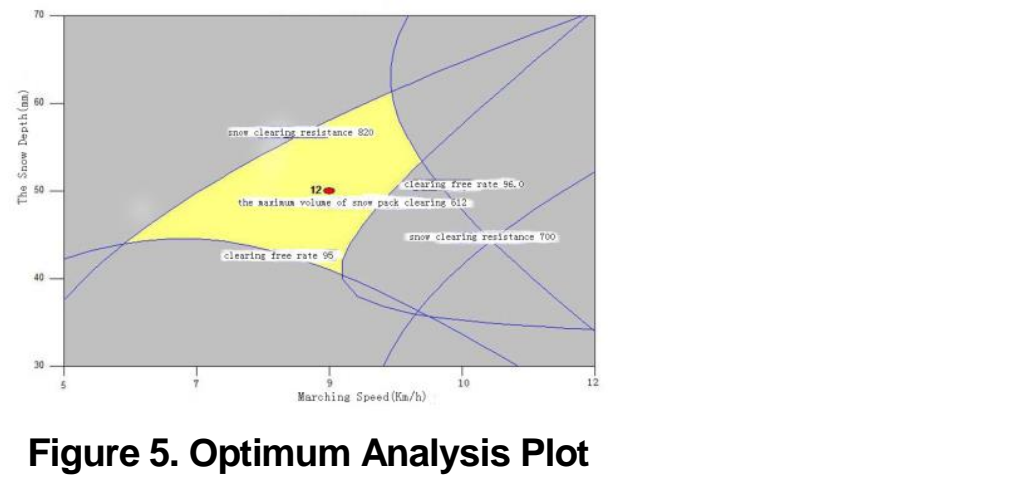

According to the principle that little snow clearing resistance, high clearing free rate, clearing large maximum volume of snow pack of the objective function, the level internal of each factor as the constraints, the optimization results shown as the yellow zone in Figure 5. When the snow clearing esistance is smaller than $820 \mathrm{~N}$, clearing free rate is greater than $96 \%$, maximum volume of snowpack clearing is greater than $612 \mathrm{~mm} 3$, the optimal combination of parameters of the snow clearing machine : marching speed as $6 \mathrm{~km} / \mathrm{h} \sim 9.7 \mathrm{~km} / \mathrm{h}$, concave disc blade angle as $19^{\circ} \sim 21^{\circ}$, concave disc marching angle as $12^{\circ} \sim 14^{\circ}$.

\subsection{Test Verification}

In the range of optimization of the best working condition, selecting the marching speed as $9 \mathrm{~km} / \mathrm{h}$, depth into snow as $50 \mathrm{~mm}$, concave disc blade angle as $20^{\circ}$, when concave disc marching angle as $13^{\circ}$ the three objective function values predicted by the software design expert are: snow clearing resistance as $764.59 \mathrm{~N}$, clearing free rate as $95.6 \%$, the maximum volume of snow pack as $616 \mathrm{~mm} 3$. After 10 times parallel test verification, mean value of snow clearing resistance as $795 \mathrm{~N}$, mean value of the clearing free rate as $95 \%$, mean value of maximum volume of snow pack as $658 \mathrm{~mm} 3$, the corresponding errors are: $4 \%, 0.6 \%, 6.8 \%$. Verification test results within the range of eptimize performance indicator, the optimization results show that the optimization is credible.

\section{Conclusion}

(1) The concave disc copying icebreaking sweeper has been developed, the machine can simultaneously complete shredding, crushing, tilt, scrape and push five functions, and has the function of copying and obstacle avoidance, according to the test finds that the copying and obstacle effect is good and efficiently solves the problem of the low free rate of solid ice and snow clearing while improving the efficiency of snow clearing. 
(2) The best structure and combination of working parameters of the copying icebreaking snow sweeper is: marching speed as $6 \mathrm{~km} / \mathrm{h} \sim 9.7 \mathrm{~km} / \mathrm{h}$, concave disc blade angle as $19^{\circ} \sim 21^{\circ}$, concave disc marching angle as $12^{\circ} \sim 14^{\circ}$.

\section{Acknowledgement}

It is a project supported by National Natural Science Foundation of China (51175226), by Jiamusi University Youth Fund (Lq2012-34), by The Education Department of Heilongjiang Province (12521536).

\section{Reference}

[1] G. Ziyi, L. Shengao and F. Zhenhua, "Technical Studies of Road Ice and Snow Removal", Transportation Science \& Technology, vol. 5, (2011), pp. 71-74.

[2] Q. Xiaojie, K. Jiangying and Q. Yingjie, "Snow Clearing Machinery Research and Discussion", Forestry" Machinery \& Woodworking Equipment, vol. 33, (2005), pp. 7-9.

[3] Z. Qijun, "Overview of Abroad Snow Removal Equipment Developments", Construction Machinery Technology \& Management, vol. 3, (2008), pp. 63-66.

[4] L. Hongying and H. Peiwen, "Road Ice and Snow Removal Technology and Development Trends", Road Machinery \& Construction Mechanization, vol. 11, (2008), pp. 18-21

[5] T. Yiqiu, "Road Ice Removal Technology in Snowstorm", Transportation Construction \& Management, vol. 3, (2008), pp. 86-87.

[6] L. Xiangdong, "Experience and Enlightenment of Urban Snow Removal Operations in Russia and Japan", Urban Management Science \& Technology, vol. 2, (2010), pp $72-74$.

[7] P. Robert, "Device for Lifing Snow From Road Surface” WO2010015992 A2, February (2010).

[8] N. Robert Gramble II, "Watertown Snow Plow Rebound Apparatus", US200903 07942A1, December (2009).

[9] D. Richard, "Embry, Indianapolis, Snow Removal Divice", US20090249658A1, October (2009).

[10] X. Xiaofen, G. Xuexun and H. Boyong, "New RoadIce and Snow Removal Vehicle Design", Special Purpose Vehicle, vol. 8, (2010), pp. 44-46.

[11] Z. Jianguo, "Simulation Analysis \& Improvement Researeh for the Front Shovel of the Multifunction Snow Remover", Jilin University, (2006)

[12] D. Hongwei, D. Hongchao and M. Wenxing, "Analysis of Snow Shovel Resistance in the Multifunction Snow Remover", Construction Machinery and Equipment, vo18, (2007), pp. 40-42.

[13] W. Longhui, "Research and Design of Vibration Flexible machine", Hongdu Science \& Technology, vol. 2, (2007), pp. 47-54.

[14] X. Zhongru, "Regression Analysis and Experimental Design", Beijing: China Agriculture Press, (1998).

[15] C. Haitao, "Development of a Baker's Garlic Seed Bulb Cluster Separator Using Response Surface Methodology", [C]/ASAE/CSAE Annual International Meeting, vol. 08, (2004), pp. 1-4.

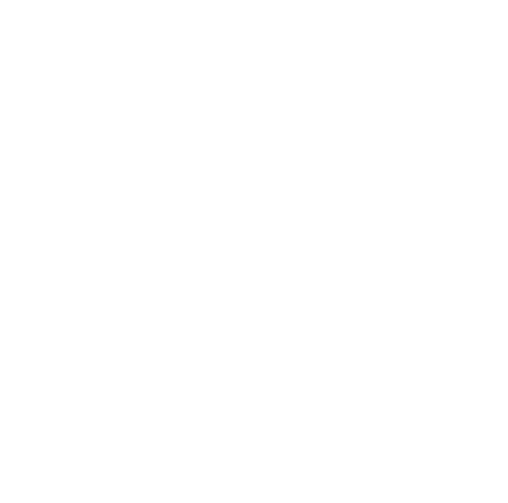


International Journal of Smart Home

Vol.8, No.3 (2014)

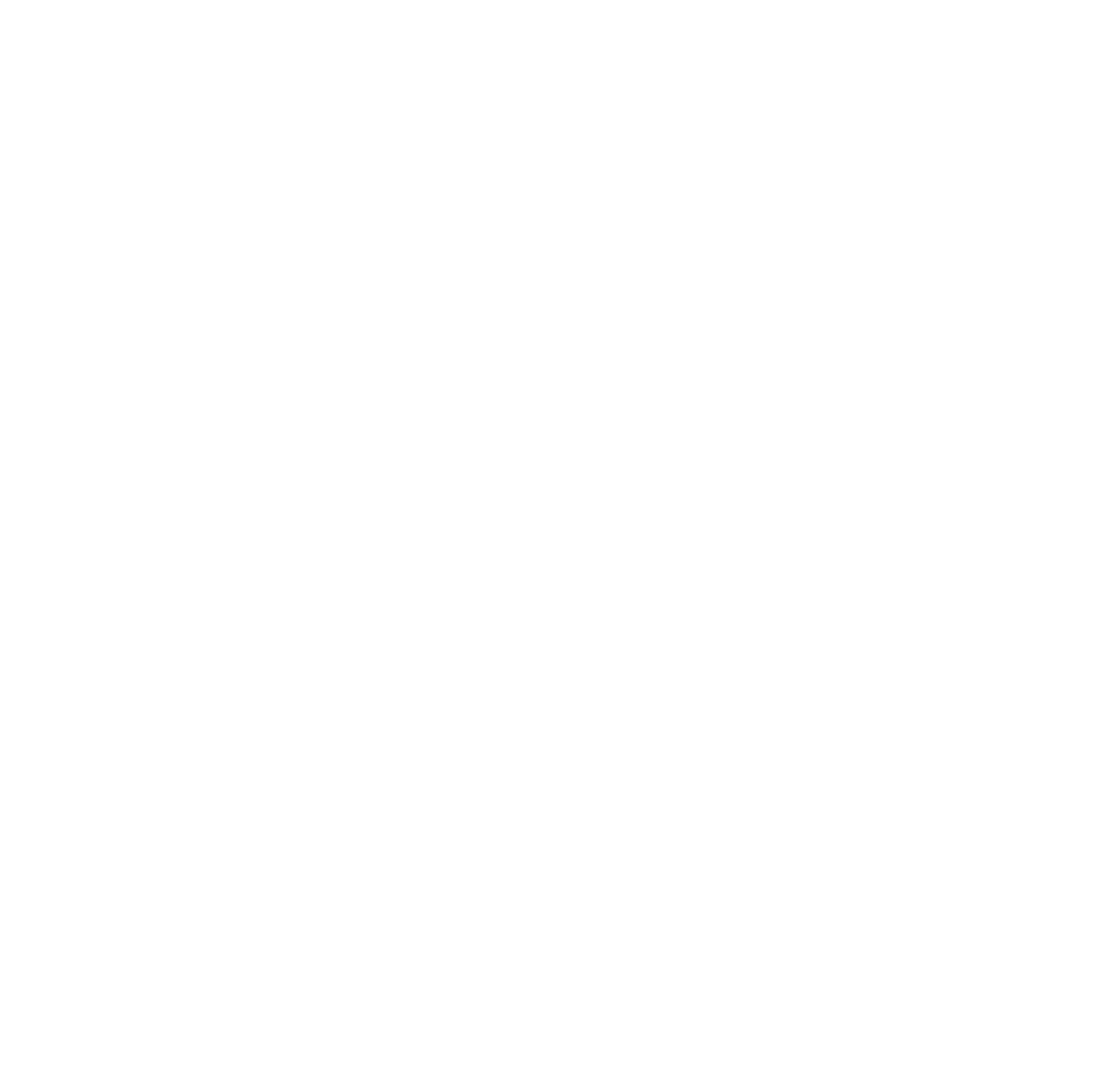

